\section{Questión}

Periodismo / Comunicación ISSN 1669-6581
- Av. $44 \mathrm{~N}^{\circ} 676,1^{\circ}$ piso

CP 1900 - La Plata - Argentina

( www.perio.unlp.edu.ar/question

La pandemia puso en evidencia la falta de un protocolo en los medios de comunicación

Emanuel Respighi - Carlos Milito - Erica Aisa

https://doi.org/10.24215/16696581e352

\title{
La pandemia puso en evidencia la falta de un protocolo en los medios de comunicación
}

\section{The pandemic highlighted the lack of a protocol in the media}

Entrevista sonora a Emanuel Respighi, periodista de Página 12 por Erica Natalia Aisa y Carlos

Milito

\section{Palabras Claves}

Periodismo - Medios de comunicación - Noticias - Emergencia - Pandemia - Protocolo Noticias falsas -

Keywords

Journalism - Media - News - Emergency - Pandemic - Protocol - Fake news -

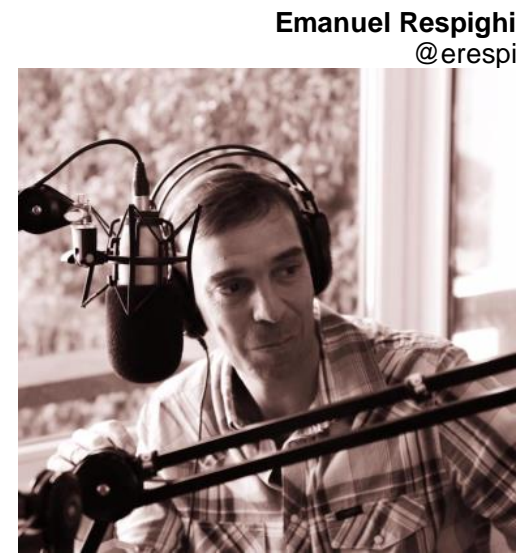


Periodista, escribe en el diario Página 12 y participa de los programas radiales Detrás de lo que vemos y Una nueva aventura en AM 750.

Erica N Aisa

https://orcid.org/0000-0002-9509-3339 Licenciada en Comunicación Social - Docente de ARGRA Escuela Integrante del IICom (Instituto de Investigaciones en Comunicación) FPyCS UNLP

Carlos Milito.

https://orcid.org/0000-0002-5874-6951 cmilito@perio.unlp.edu.ar

Magister en Comunicación y gestión de procesos comunicacionales FPyCS UNLP Profesor Titular del Taller de producción de contenidos y narrativas sonoras y radiales Director de la Especialización en Comunicación radiofónica - FPyCS UNLP Coordinador de 1894radioonline de Villa Elisa, Provincia de Buenos Aires Locutor comercial de Relatores. Transmisiones Deportivas por la app y AM530 Somos Radio Integrante del IICom (Instituto de Investigaciones en Comunicación) FPCS UNLP

\section{Enlace}

https://ar.ivoox.com/es/51717831 